\title{
Flow Simulation to Determine the Effects of Shrouds on the Performance of Wind Turbines
}

\author{
Peter E. Jenkins, Abdalfadel Younis \\ Mechanical Engineering Department, University of Colorado, Denver, USA \\ Email: peter.jenkins@ucdenver.edu
}

Received 15 June 2016; accepted 28 August 2016; published 31 August 2016

Copyright (C) 2016 by authors and Scientific Research Publishing Inc.

This work is licensed under the Creative Commons Attribution International License (CC BY). http://creativecommons.org/licenses/by/4.0/

(c) (i) Open Access

\begin{abstract}
This paper describes a flow simulation model used to determine the effects of a shroud on the performance of a wind turbine. Also, it focuses on comparing the standard type of wind turbinesupwind turbine with three blades fixed on a horizontal axis-with a new type that is called a shrouded wind turbine. In addition, the two types of turbines are compared in terms of velocities profiles, pressure distribution and power output when applying four different velocities of winds: $10,20,30,40 \mathrm{mph}$. Numerical values and graphs are highlighted in order to show the main differences between the shrouded turbine and the conventional one. Finally, a conclusion and some recommendations are provided to summarize the scope of this research and give a better prediction for a future optimal design of the shrouded turbines.
\end{abstract}

\section{Keywords}

Wind Turbine, Flow Simulation, Shroud

\section{Introduction}

Since conventional energy sources have their disadvantages in regards of environmental pollution, fuel costs, and other aspects, researchers and engineers have been working together to find alternative energy sources for many years; this is because of the increasing demand of electrical power that doubles every six to 10 years in the United States [1]. As a result, the usage of renewable energy sources has expanded during the past ten years because of the demand to provide clean power. The usage of wind power, a primary example of a renewable energy source, has been one of the fastest growing technologies in the world [2]. Winds energy offers an effective way for generating the electrical energy due to the trend of the world to be independent on the fuel-based 
sources such as oil and gas; subsequently, the wind turbine technology produces electrical energy without greenhouse effects or harmful polluting gasses [3]. Also, generating electric power via wind turbines is affordable with low installation and maintenance costs unlike other conventional power plants.

A wind turbine is a machine that converts wind power into electricity through a set of components [4]. The simplified principle of wind turbine is that wind energy exerts force on blades of a rotor that is connected to a shaft, gear box, and finally a generator that changes the wind force through the rotational movement of the shaft to electrical power. These days, the productivity of winds turbines starts from 0.3 MW up to 7.5 MW. It is also expected to reach to 20 MW by 2020, as shown in Figure 1.

\section{Configurations of Wind Turbines}

Wind turbines are operated in two different configurations the horizontal-axis wind turbines (HAWTs) and the vertical-axis wind turbines (VAWTs), as shown in Figure 2. Recently, most of the used wind turbines are the horizontal-axis wind turbines that have their axis parallel to the flow of winds [5] [6]. These types of turbines have specific operational features. For example, they generally have low cut-in wind speeds. Also, the power produced from horizontal-axis wind turbines is much greater than that produced from vertical-axis wind turbines due to a better power coefficient for the horizontal-axis wind turbines.

Horizontal-axis wind turbines are also sorted by the numbers of blades they use: one-blade, two-blade, threeblade, and multi blade wind turbines, as shown in Figure 3. Even though both single and two-bladed turbines do not cost that much, they are still used rarely because of their need of higher wind speeds to produce the same amount of power that is produced by the three-blade type. The multi blade types are usually used as windmills for pumping water; therefore, most of the produced power is via commercial wind turbines that have three blades.

The horizontal-axis wind turbines can be also classified depending on the way in which rooters face winds. This means that they can be classified into upwind or downwind turbines, so, as shown in Figure 4. If the rotor is fixed before the tower so that winds hit it before the tower, the wind turbine is called an upwind wind turbine, while if the rotor is integrated with the nacelle after the tower, the wind turbine is called a downwind wind turbine [7].

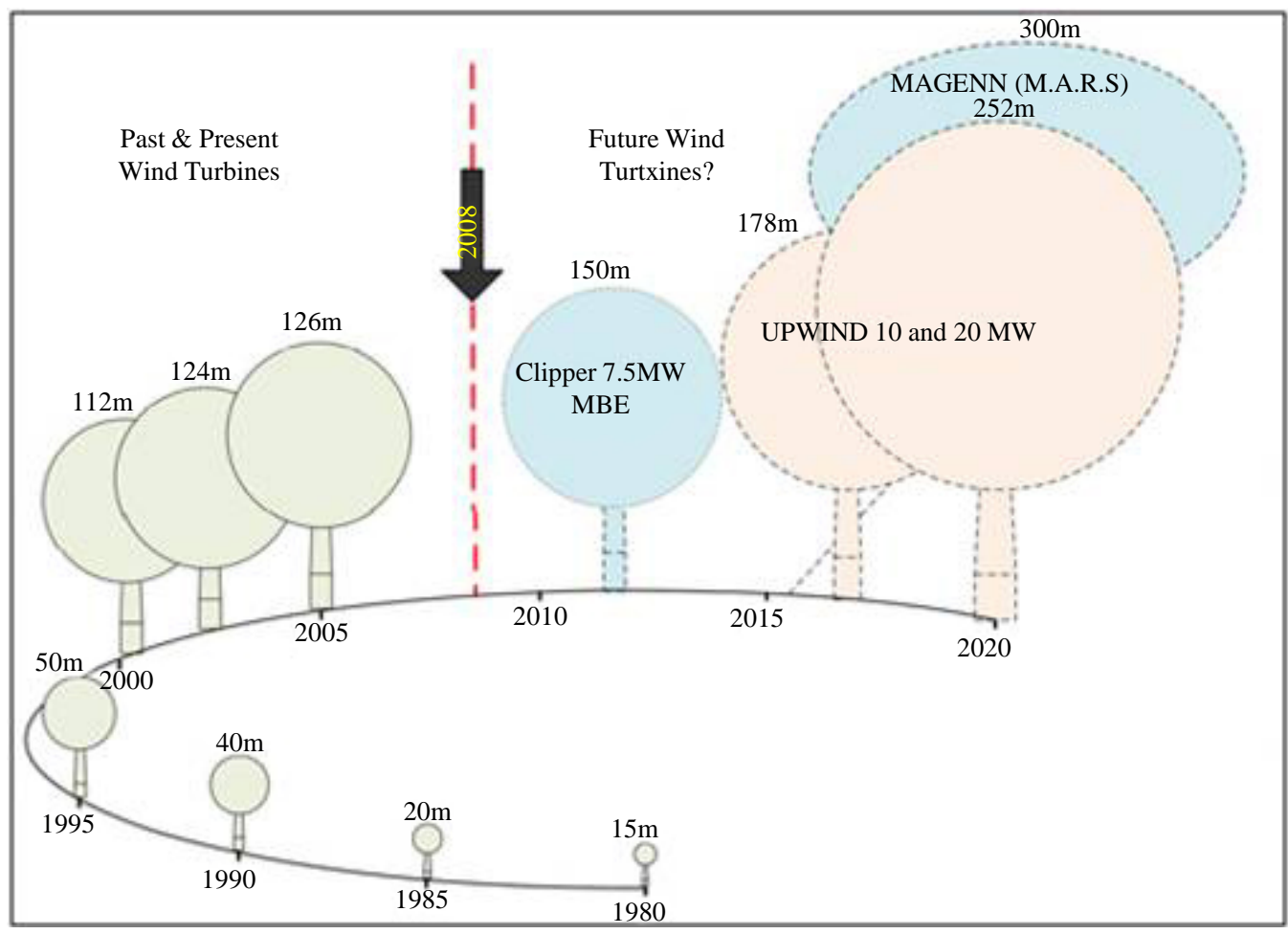

Figure 1. Development of wind turbines. 


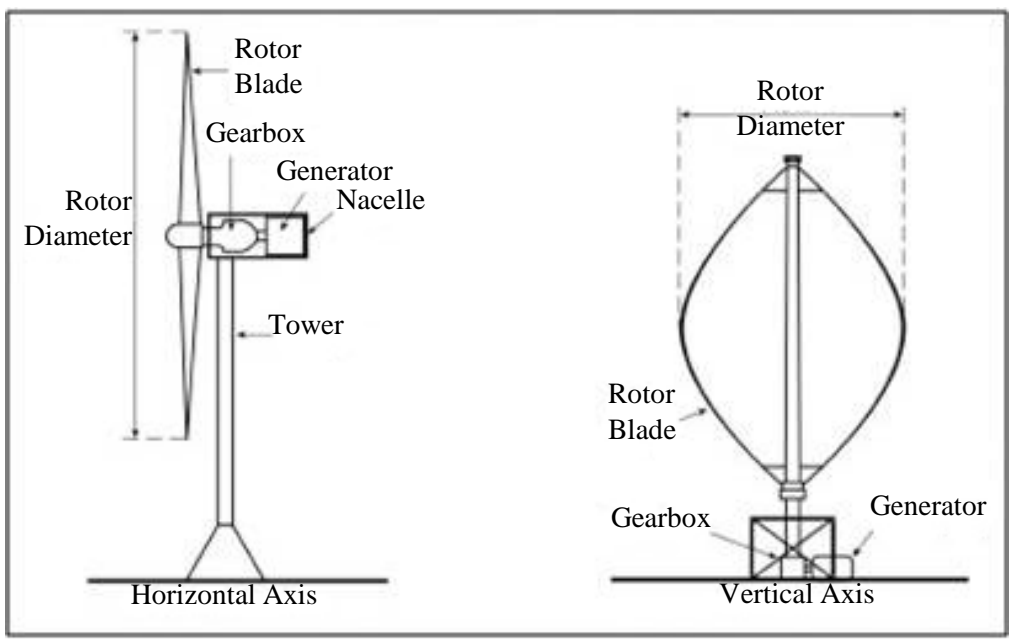

Figure 2. Configurations of wind turbines.

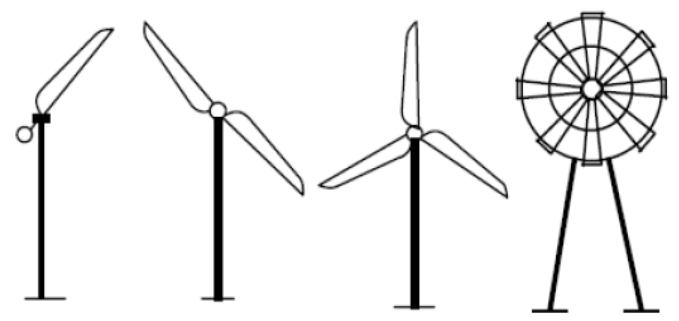

Single bladed, two bladed, three bladed and multi bladed turbines

Figure 3. Classification of wind turbines.

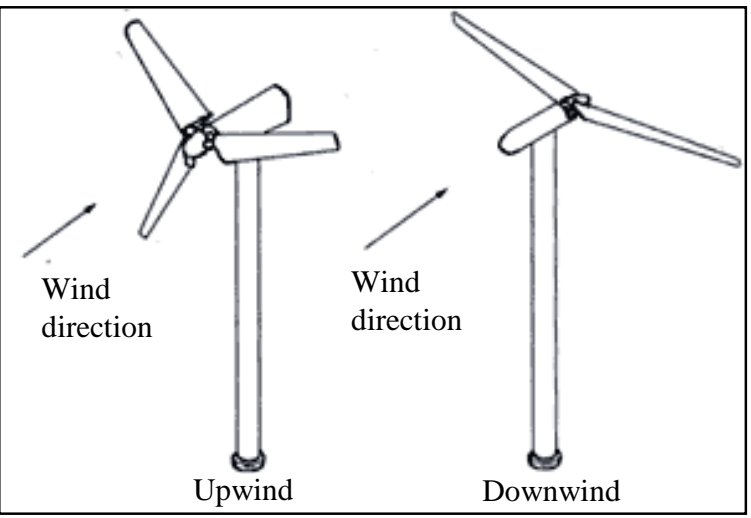

Figure 4. Upwind and downwind wind turbines.

\section{Shrouded Wind Turbines}

Shrouded wind turbines are advanced versions of the conventional types of wind turbine. The first appearance of these kinds of wind turbines was through the last century when an inventor called Dew Oliver installed his first ducted turbine in 1920 (Wind Works Organization, 2009). However, this ducted turbine had its disadvantages, and it had not been developed until 2005 when a Swiss company displayed a new type of shrouded turbine called the Dew's turbine.

The shrouded wind turbine and the conventional horizontal-axis wind turbine have same configurations and components, but the shrouded wind turbine has an extra component called the shroud that holds the blades and 
nacelle inside, as shown in Figure 5. The feature that allows the shrouded wind turbine to have a better performance than the conventional ones is that they produce more power per unit frontal area, resulting in a smaller size and lower cost for parts [8].

The main effect of the shroud on the turbine is based on the working principle of diffusers. That is, if an extended diffuser is used, the speed of winds is faster at the entrance of the diffuser. Also, by adding a circular frame called "brim" at the end of the diffuser, vortexes are formed behind it, forming a low-pressure region behind the diffuser, as shown in Figure 6.

This kind of design results in an increase of mass flows drawn into the diffuser; hence, the speed of the winds gets higher at the entrance of the shroud, causing higher rotational speed of the blades of the turbine, which results in more produced power generated from the turbine.

In this section, the designs and simulations are described for both regular and shrouded turbines that were designed by using SolidWorks2015. The basic wind turbine was the same for both designs. Also, the actual wind turbine model used for this simulation is a three megawatt-upwind turbine with horizontal axis made by Vestas, as shown in Figure 7. Both the regular and shrouded configurations have same components, except that the shrouded wind turbine is modified by adding a shroud surrounds the blades and the nacelle. This shroud consists of a diffuser and brim integrated together. This allows the shrouded turbine to produce more power than the regular one by producing a higher air flow over the blades.

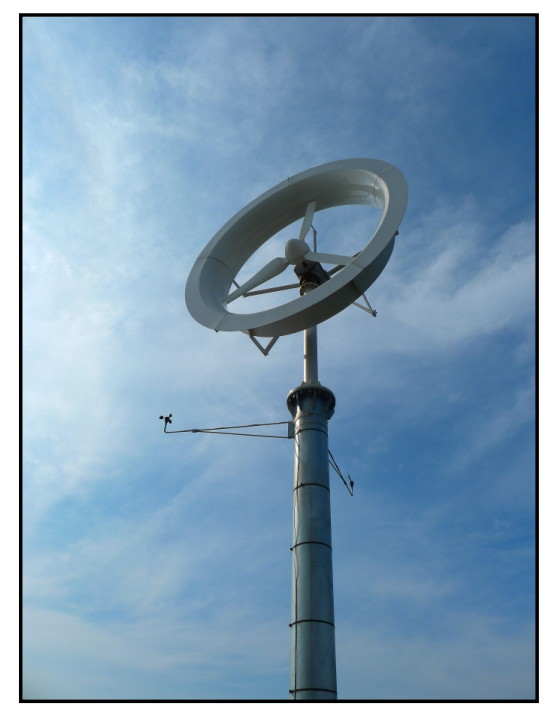

Figure 5. Shrouded wind turbine.

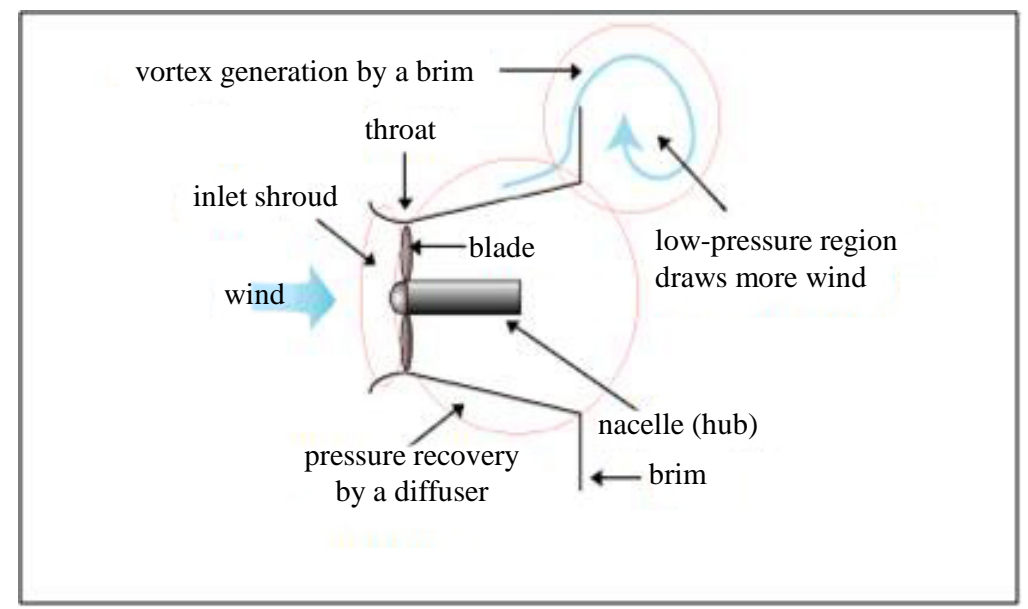

Figure 6. Working principles of shrouds and brims. 


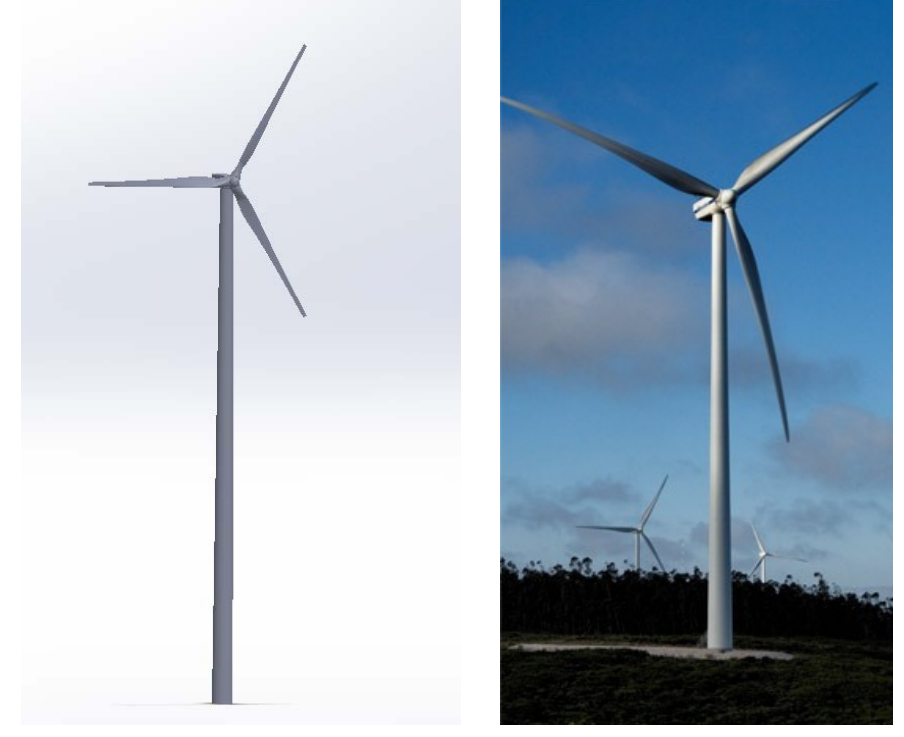

Figure 7. Solid works model and the actual turbine.

\section{Conventional and Shrouded Wind Turbine}

\subsection{Dimensions of Conventional Wind Turbine}

As mentioned above, the model of the conventional wind turbine is designed in SolidWorks2015. The main dimensions that were used are taken from the catalog of V90-3MW wind turbine by Vestas, as shown in Table 1.

\subsection{Simulation of Conventional Wind Turbine}

To simulate the conventional wind turbine, an animation was run using SolidWorks2015, details of the pressure and velocity distributions were required; therefore, the trajectories of the flow and the gradients of both speed and pressure were drawn so the changes in the pressure and velocity were translated into numbers. The trajectories of the flow are colored so that the gradients of the speed and pressure are highlighted, as shown in both Figure 8 and Figure 9, so the value of the speed of the wind at the surfaces of the blades can be obtained to calculate the exerted power by the wind turbine through an EES code.

\subsection{Dimensions of Shrouded Turbine}

For the shrouded turbine, as mentioned above, the only thing that is added to the regular wind turbine to be changed to a shrouded one is a shroud. The dimensions of the shroud and the position of the blades inside it are shown in Figure 10.

There are various types of shrouds. Some of them are thinner that others, but to get the best performance, the shroud should have a longer diffuser and brim to cause vortexes as much as possible so more flow can be entrained to increase the velocity of the entering flow. This increase in the velocity of the flow increases the rotational speed of the wind turbine shaft and results in an increase in output power. However, increasing the lengths of the diffuser and brim could adversely affect the durability of the shroud wind turbine because of the increases of weights and stresses on them. For the simulation of the shrouded turbine, the dimensions of the used shrouded is governed by a set of equations that calculate the related parameter as functions of the diameter of the rotor (Dr):

$$
\begin{gathered}
L t=1.47 D \\
L=\frac{L t}{2} \\
D=[D r+(0.02 D r)]
\end{gathered}
$$


Table 1. Design details of conventional wind turbine.

\begin{tabular}{|c|c|c|c|c|c|c|c|}
\hline & Rooter & & Nacelle & & Tower & & Hub \\
\hline Rotor diameter $(m)$ & 90.1771 & Height $(m)$ & 4 & Height $(m)$ & 150 & Maximum diameter $(m)$ & 3.6 \\
\hline Swept area $\left(m^{2}\right)$ & 6387 & Length $(m)$ & 9.65 & & & Maximum width $(m)$ & 4.2 \\
\hline Length of blade $(m)$ & 43.2885 & Width $(m)$ & 8.85 & & & Length $(m)$ & 4.4 \\
\hline
\end{tabular}

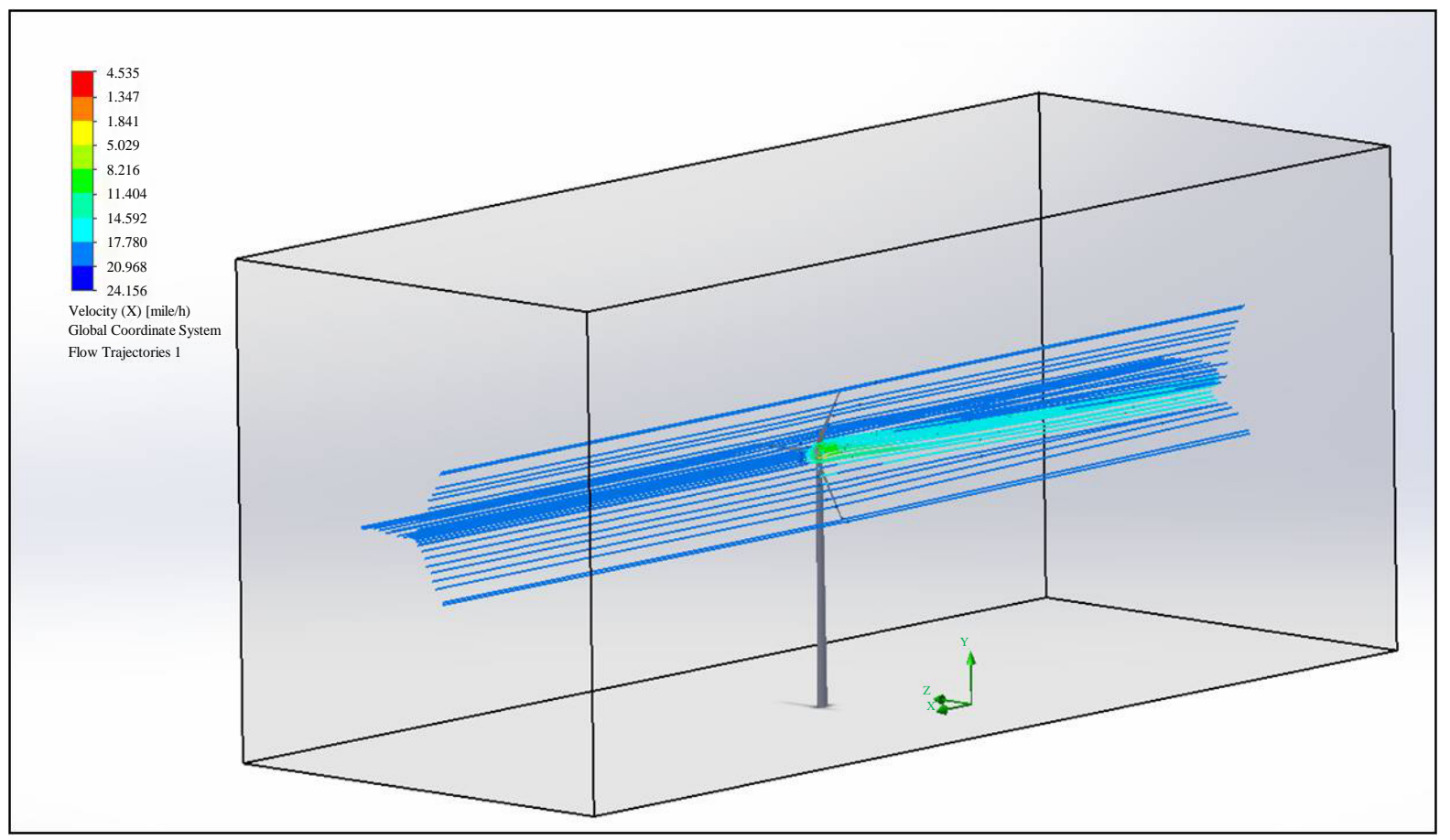

Figure 8. Velocity gradients and flow trajectories.

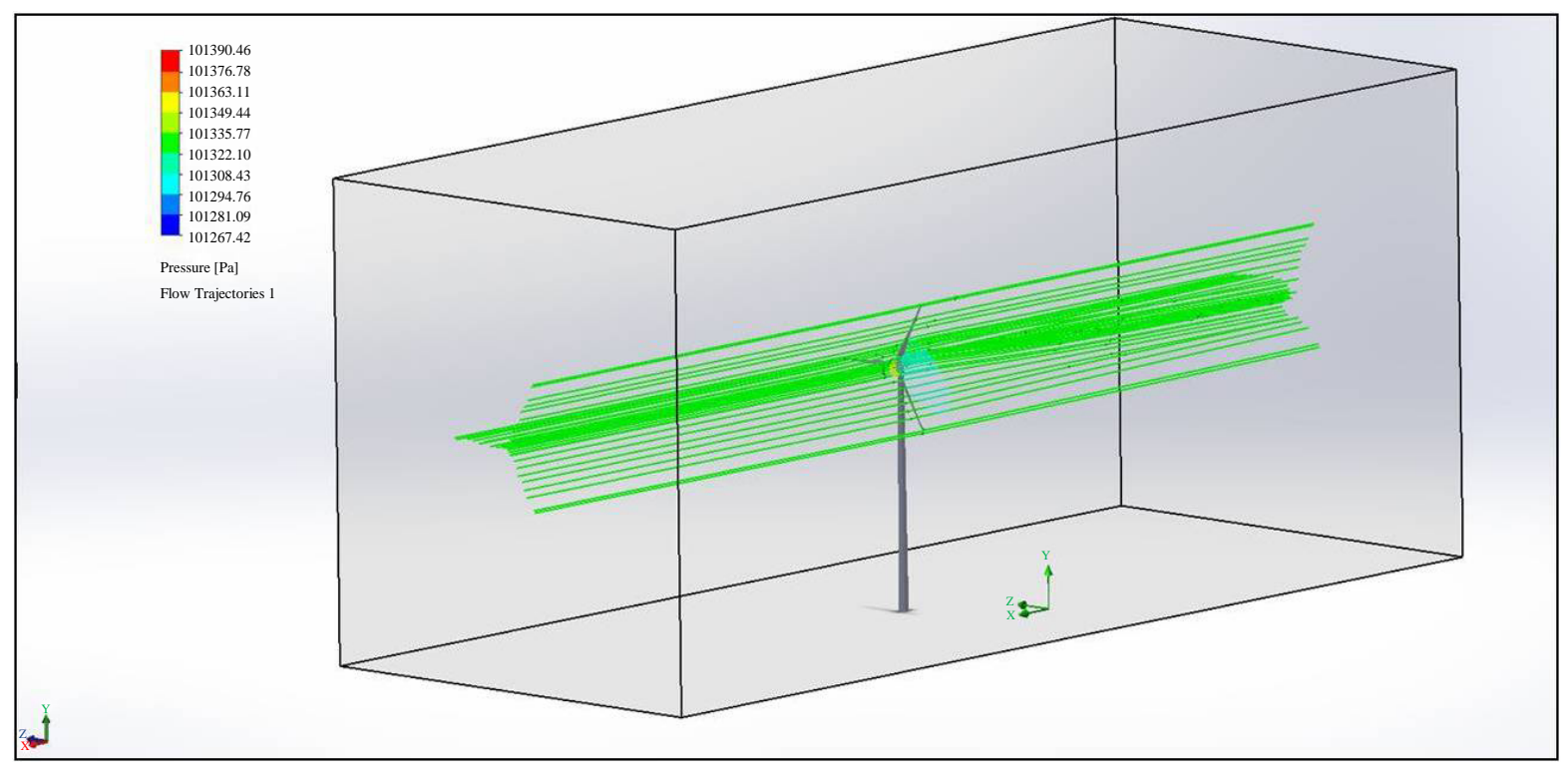

Figure 9. Pressure gradients and flow trajectories. 


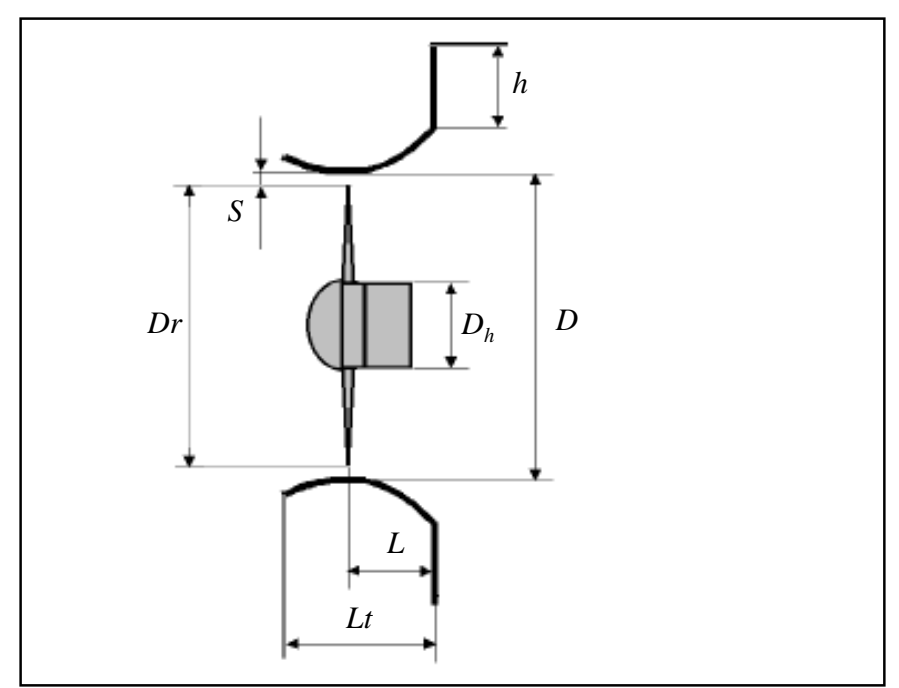

Figure 10. Dimensions of the shroud.

\subsection{Simulation of Shrouded Wind Turbine}

The pressure and flow velocities for the conventional and shrouded turbine were the same for the air flowing toward the blades of the turbine. However, further details of the pressure and velocity distributions were required; therefore, the trajectories of the flow and the gradients of both the speeds and pressures were drawn so that the change in pressure and velocity were translated into numerical values. The trajectories of the flow show that because of the design of both the diffuser and brim, large vortices exist behind the shroud, creating a low pressure region and allow of an increase in air flow inside the diffuser, as shown in Figure 11. The trajectories have different colors so that the gradients of speed and pressure are highlighted, as shown in both Figures 12-14.

\section{EES Programming}

The EES program was written to solve the equations that govern the calculations of the produced power from the regular and shrouded turbines at speeds of 10, 20, 30, and $40 \mathrm{mph}$. However, analyzing a wind turbine can be achieved in different methods such as the Weibull Rayleigh analysis [9]. In this report, the distribution of Rayleigh was used to calculate the efficiency and power produced by the wind turbines.

\section{Governing Equations}

According to Rayleigh's distribution, the efficiency, as presented in Equation (5.1.1), is the result of dividing the annual energy delivered from the turbine by the available energy from the wind. The annual delivered energy, as presented in Equation (5.1.2), equals to the numbers of hours in a year times the capacity factor of the turbine, as presented in Equation (5.1.3), and times the rated power produced that is obtained from the power curve of the actual turbine at the rated speed of wind, as shown in Figure 15. The actual energy of the wind equals to the average rated power multiplied by the number of hours in a year, as shown in Equation (5.1.4).

$$
\begin{gathered}
\eta=\frac{E_{\text {annual }}}{E_{\text {wind }}} \\
E_{\text {annual }}=8760 \times P r \times C F \\
C F=0.087 \times\left(15-\frac{P r}{D r^{2}}\right) \\
E_{\text {wind }}=8760 \times \overline{P r}
\end{gathered}
$$




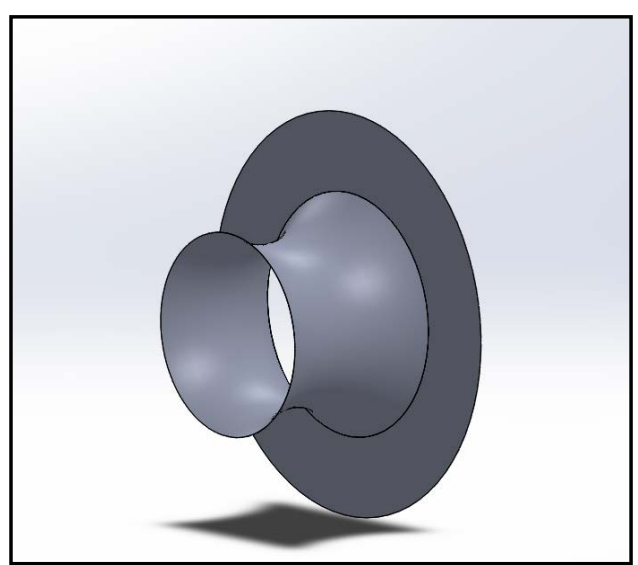

Figure 11. Shroud on SolidWorks2015.

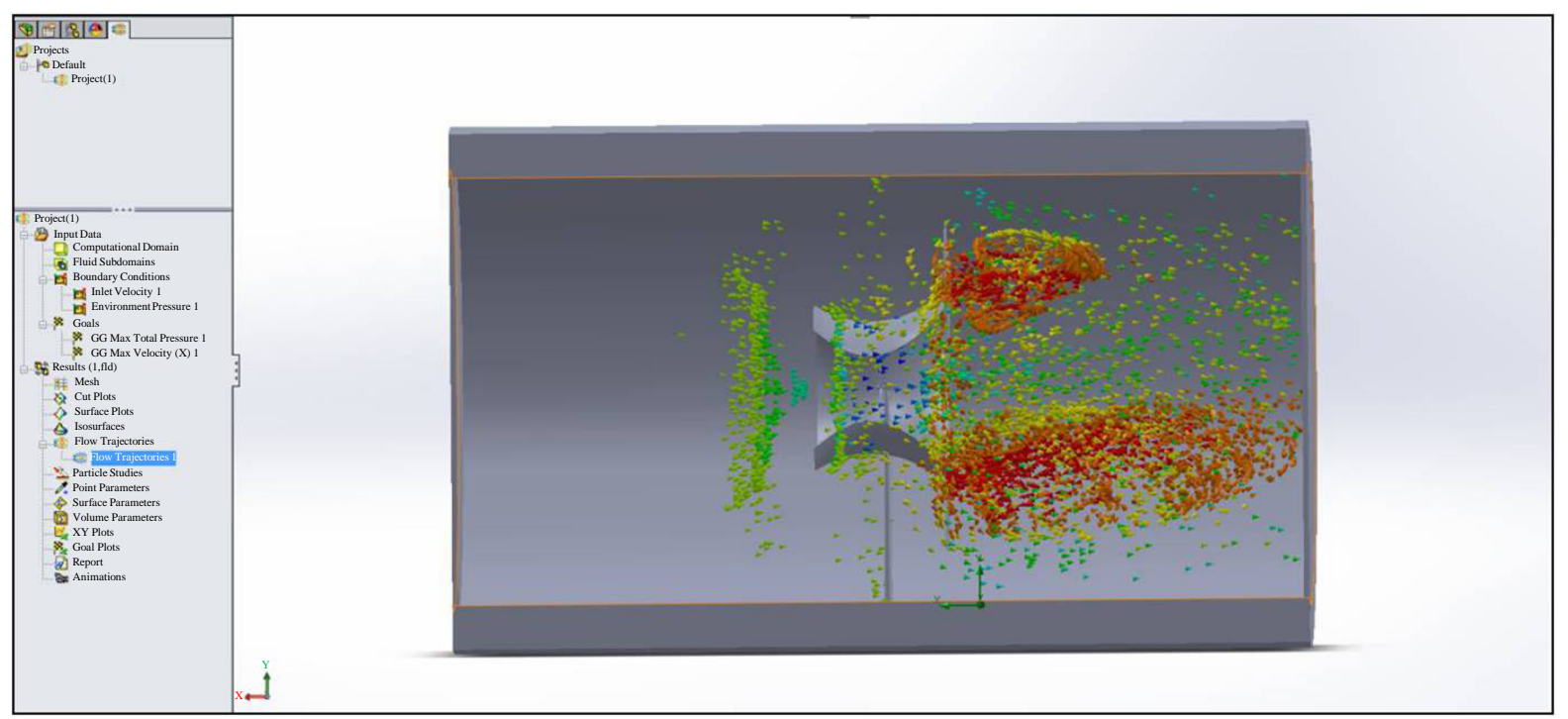

Figure 12. Vortices behind the shroud's brim.

The average rated power in Equation (5.1.4) can be calculated as a function of the swept area by the rotor, density of air, and cubic of the rated wind speed, as presented in Equation (5.1.5).

$$
\overline{\operatorname{Pr}}=\frac{6}{\pi} \times \frac{1}{2} \times \rho_{\text {air }} \times A_{\text {rotor }} \times \bar{v}_{r}^{3}
$$

Also, another parameter that is used to evaluate the productivity of wind turbines is the actual produced power, which is the net power that is collected at the output of the generator. The average actual produced power equals to the result of multiplying the efficiency by the power of winds, as presented in Equation (5.1.6).

$$
\bar{P}_{\text {act }}=\eta \times \bar{P}_{\text {wind }}
$$

The power obtained from the wind is also obtained using Equation (5.1.7).

$$
\bar{P}_{\text {wind }}=\frac{6}{\pi} \times \frac{1}{2} \times \rho_{\text {air }} \times A_{\text {rotor }} \times \bar{v}^{3}
$$

Since both configurations use the same model of turbines, all these equations are applicable for both designs. But the only thing that makes the results of both simulations differ from each other is the frontal air speed of wind at the surfaces of rotor's blades, $\bar{v}$, which affects the power obtained from the wind. For instance, for the 


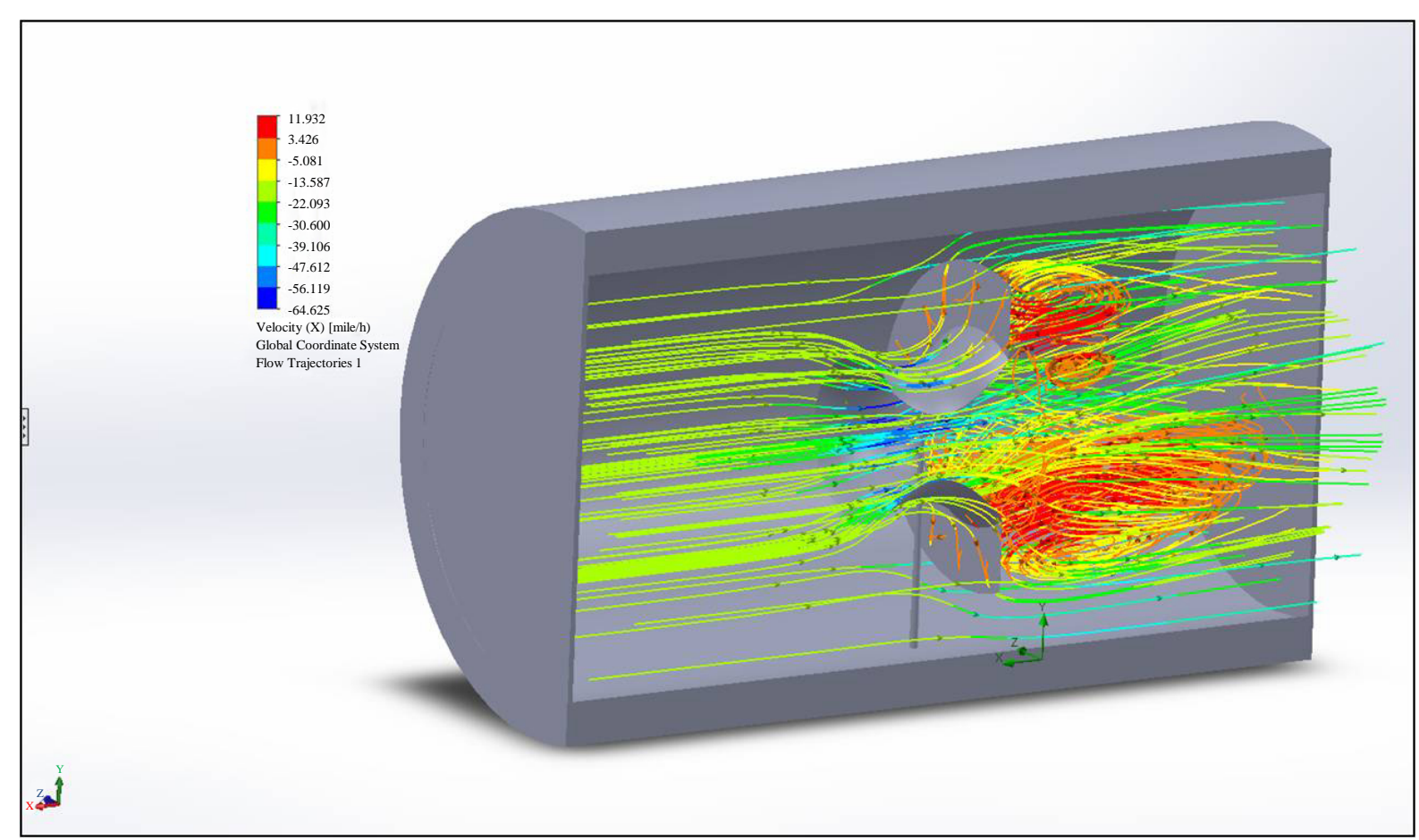

Figure 13. Velocity gradients and flow trajectories.

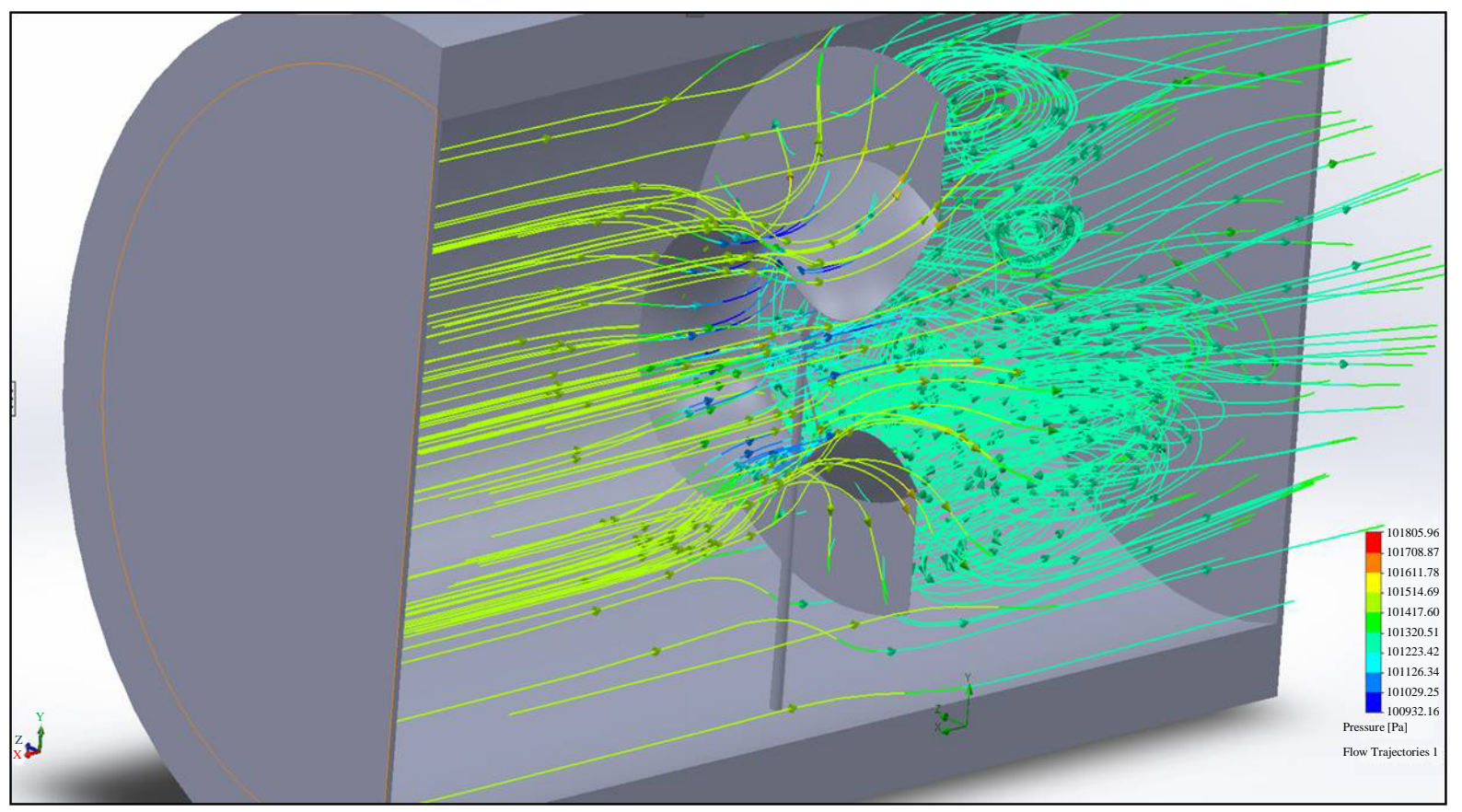

Figure 14. Pressure gradients and flow trajectories.

shrouded wind turbine, because of the design of the diffuser, the flow at the entrance of the diffuser gets accelerated, so the frontal wind speed at the surface of the blades is increased which increases the power produced from the turbine. However, for the regular wind turbine, since no diffuser surrounds the blade to lower the pressure and increase the wind speed toward the blades, the flow gets blocked by the blades and disperses, losing some of its kinetic energy. The effect of the diffuser can be noticed when comparing both numerical values of 


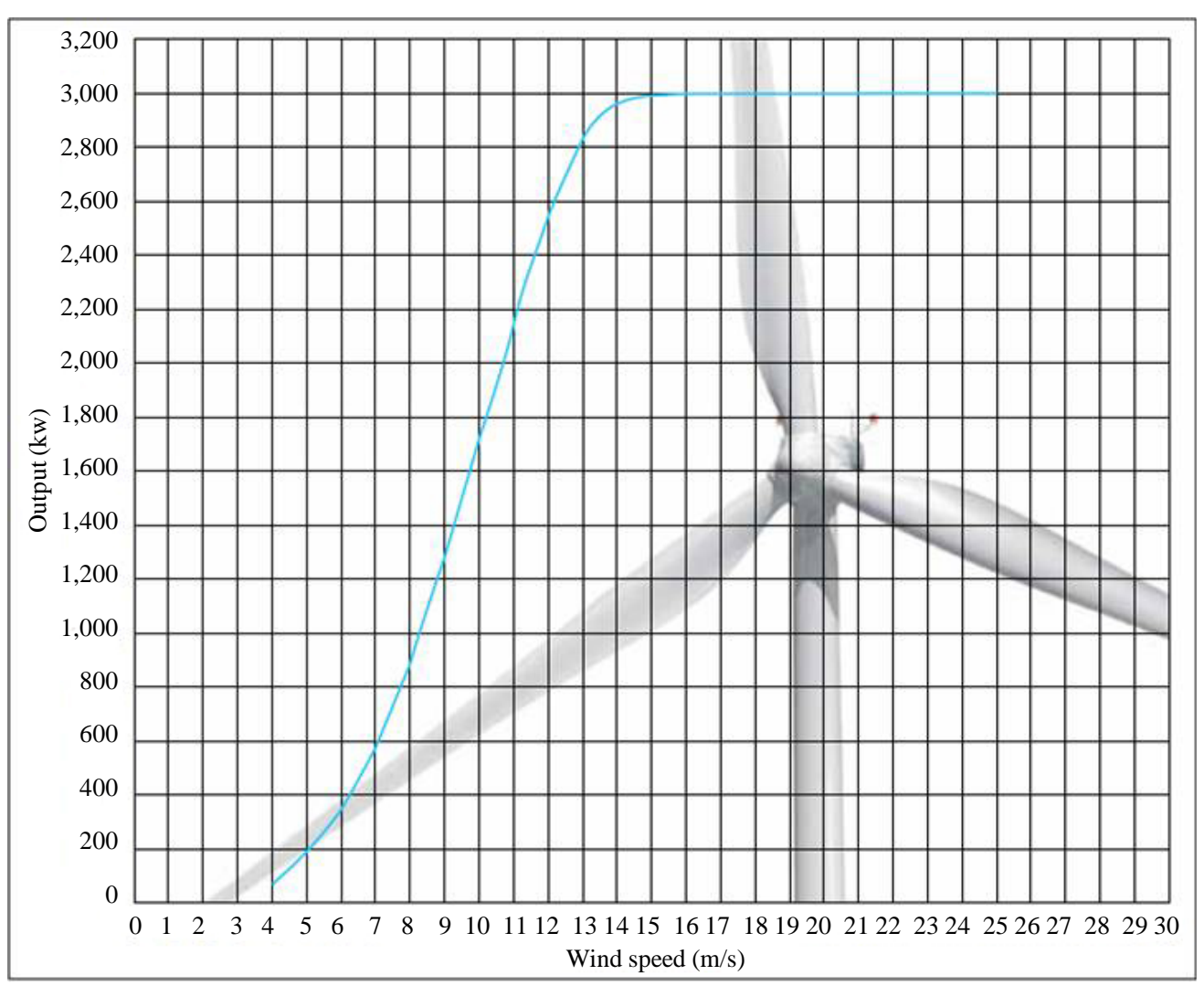

Figure 15. Power curve of V90-3.0 MW turbine.

the frontal wind speeds for both configurations at every single applied speed, as clarified in both Table 2 and Table 3.

\section{Results and Discussion}

The results that are collected from the simulation of SolidWorks2015 and EES have been plotted for both types of configurations. These plots show that there are disparities between both types in terms of the following parameters:

- Front pressure

- Back pressure

- Back velocity

- Produced power

\subsection{Front Pressure}

In this section of the research report, a front pressure is a term used to call the pressure in the flow that was measured exactly over the front surface of the blades of the turbines during the simulation. Drawing this pressure for both turbines versus the applied speed of wind shows a large disparity between them. Table 4 and Table 5 show the applied speed of winds in mph, and resulting front pressures.

According to both Table 4 and Table 5, and Figure 16, for the conventional wind turbine, when increasing the velocity of winds towards the blades, the flow gets blocked by the blade, so the layers of the flow at the surface of the blades get reduced, causing an increase in the pressure of the flow. However, for the shrouded turbine, and because of the existence of the shroud, the front pressure decreases when increasing the speed of winds. For instance, at $10 \mathrm{mph}$ the related front pressure is $101,278.49 \mathrm{~Pa}$, while at the speed of $40 \mathrm{mph}$ the recorded pressure is 100,956.19 Pa. by looking at the two values, it is clear that there is a big difference, and that what explains the effect of the diffuser on the performance of the turbine. To show the different between usages 
Table 2. Applied speeds of winds on conventional wind turbine and front speeds over blades' surface.

\begin{tabular}{ccccc}
\hline Applied wind speed $(m p h)$ & 10 & 20 & 30 & 40 \\
Front Speed $(m / s)$ & 3.9191 & 9.1178 & 11.5962 & 15.7108 \\
\hline Table 3. Applied speeds of winds on shrouded wind turbine and front speeds over blades' surface. \\
\hline Applied wind speed $(m p h)$ \\
Front speed $(m / s)$ & 10 & 20 & 30 & 40 \\
\hline
\end{tabular}

Table 4. Applied speeds of winds on conventional wind turbine and front pressures over blades' surface.

\begin{tabular}{ccccc}
\hline Applied wind speed $(\mathrm{mph})$ & 10 & 20 & 30 & 40 \\
Front pressure $(\mathrm{Pa})$ & $101,334.13$ & $101,354.1$ & $101,365.9$ & $101,449.9$ \\
\hline
\end{tabular}

Table 5. Applied speeds of winds on shrouded wind turbine and front pressures over blades’ surface.

\begin{tabular}{cccc}
\hline Applied wind speed $(m p h)$ & 10 & 20 & 30 \\
Front pressure $(\mathrm{Pa})$ & $101,278.49$ & $101,236.65$ & $101,123.49$ \\
\hline
\end{tabular}

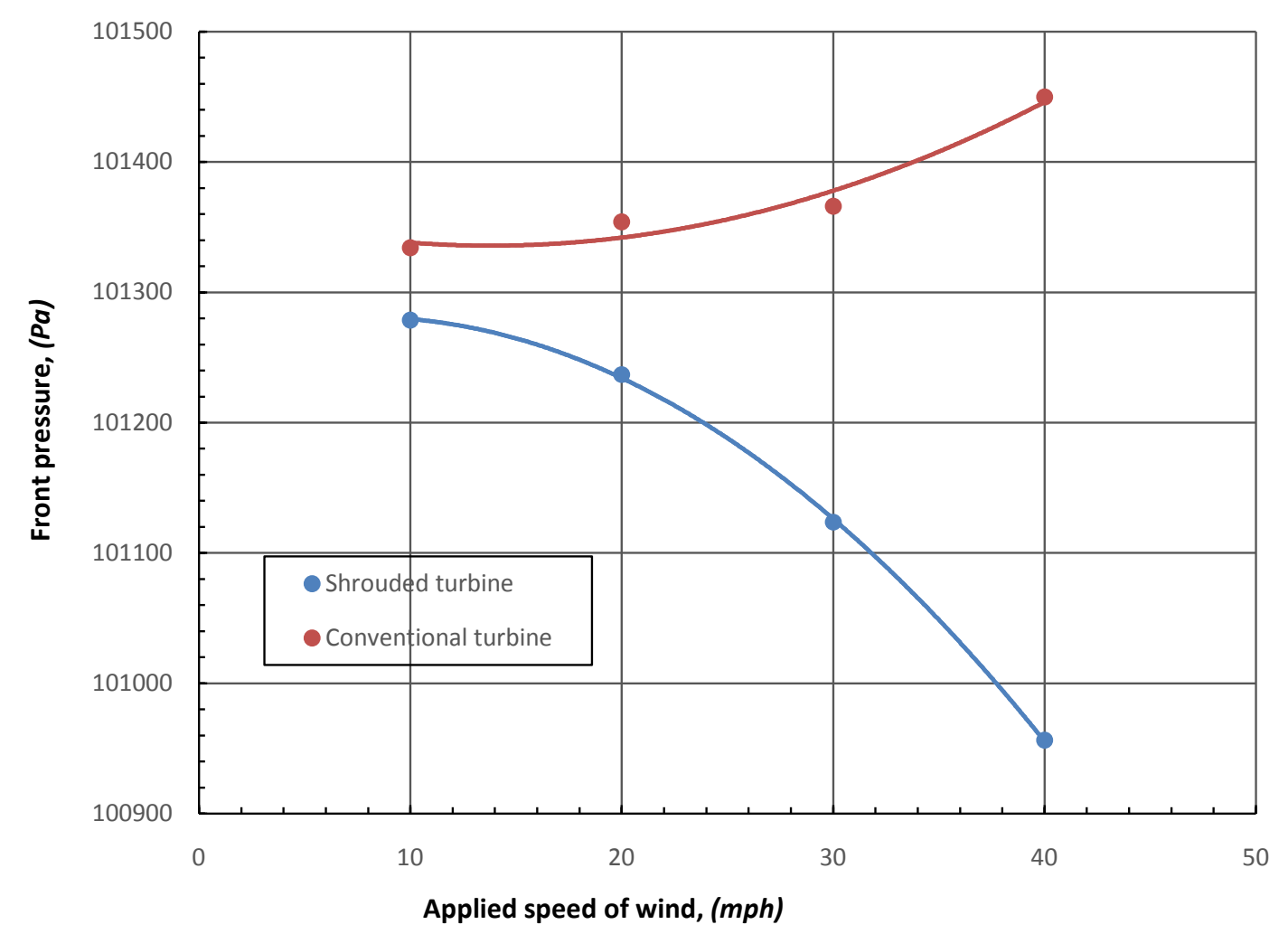

Figure 16. Applied speeds of winds against front pressures.

the conventional wind turbine and the shrouded turbine, the data in both tables were drawn, as shown in Figure 16.

\subsection{Back Pressure}

The back pressure is a term used to call the pressure in the flow that was measured exactly right on the rear surface of the blades of the turbines during the simulation. 
According to Table 6, and Figure 17, for the conventional wind turbine, when applying winds with different velocities, the kinetic energy of winds gets consumed by the blade which results in decrease in pressure behind the blades. By looking at Table 6, it is noticeable that the decrease in the back pressure is not that large due to losses in the energy of winds since a part of it is dispersed far way of the blades. Also, when increasing the value of the applied velocity of wind, the value of the decrease in the back pressure is not that large. For example, when applying a velocity of $40 \mathrm{mph}$, the resulted back pressure is 101,122.4 Pa which is not that large when compared to the resulted value when applying the same value with the existence of the shroud.

However, according to Table 7, and Figure 17, when applying same velocities of winds on the shrouded turbine, it is clear that because of the shroud the pressure behind the blades gets lowered more than the back pressure behind the blades of the conventional turbine. This drop in the pressure is a result of the low-pressure region that is caused by the brim at the end of the shroud; this is resulted in a decrease of the value of the back pressure when applying a wind speed of $40 \mathrm{mph}$. When comparing both values of back pressures for both turbines at the same applied speed of winds, it is clear that the measured value of the back pressure of the shrouded wind - 100,160.63 Pa - is lower than that value for the conventional turbine which is 101,122.7 Pa. This boosts the velocity of the flow at the entrance of the shroud, causing an increase in the produced power.

\subsection{Back Velocity}

The back velocity is the velocity of the flow that was measured on the rear surface of the blades of the turbines during the simulation.

According to Table 8, and Figure 18, for the conventional wind turbine, when applying winds with different

Table 6. Applied speeds of winds on conventional wind turbine and back pressures over blades' surface.

\begin{tabular}{ccccc}
\hline Applied wind speed $(m p h)$ & 10 & 20 & 30 & 40 \\
Back pressure $(\mathrm{Pa})$ & $101,320.8$ & $101,302.9$ & $101,200.6$ & $101,122.7$ \\
\hline
\end{tabular}

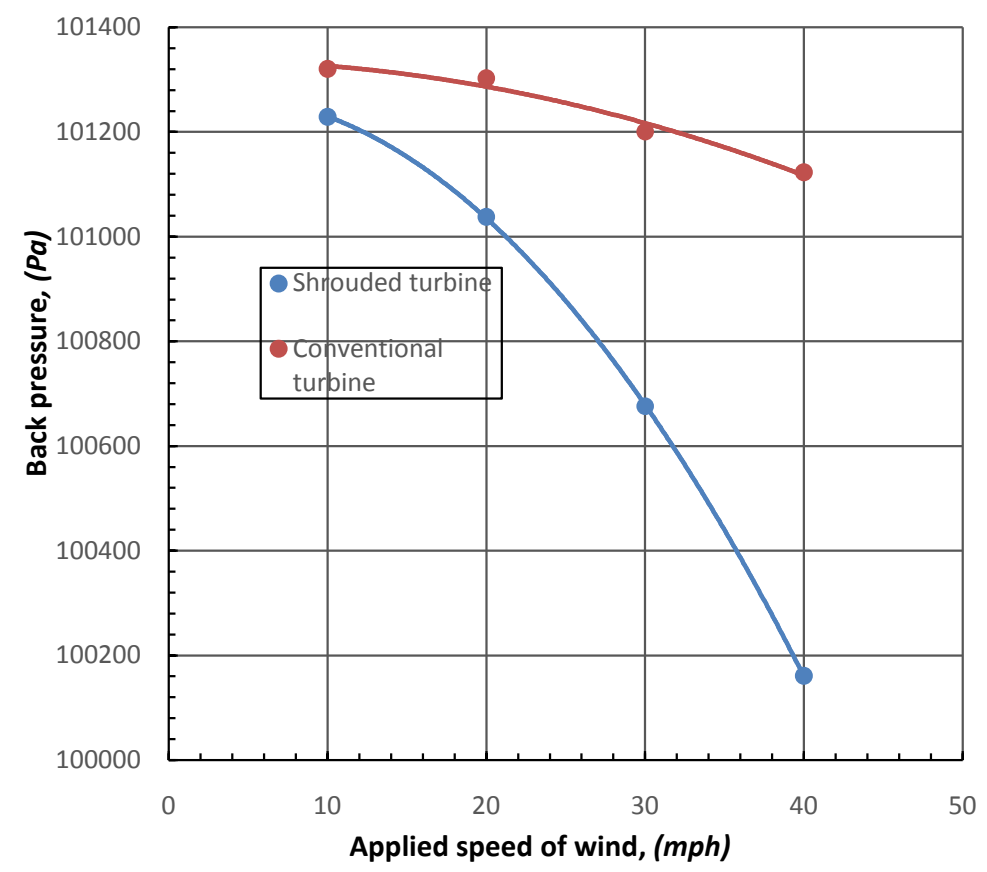

Figure 17. Applied speeds of winds against back pressures.

Table 7. Applied speeds of winds on shrouded wind turbine and back pressures over blades’ surface.

Applied wind speed $(m p h)$

Back pressure $(\mathrm{Pa})$
10

$101,228.92$
20

101,037.9
30

$100,675.81$
40

$100,160.63$ 
Table 8. Applied speeds of winds on conventional wind turbine and back velocities over blades' surface.

\begin{tabular}{ccccc}
\hline Applied wind speed $(m p h)$ & 10 & 20 & 30 & 40 \\
Back velocity $(m p h)$ & 5.504 & 12.249 & 14.382 & 16.708 \\
\hline
\end{tabular}

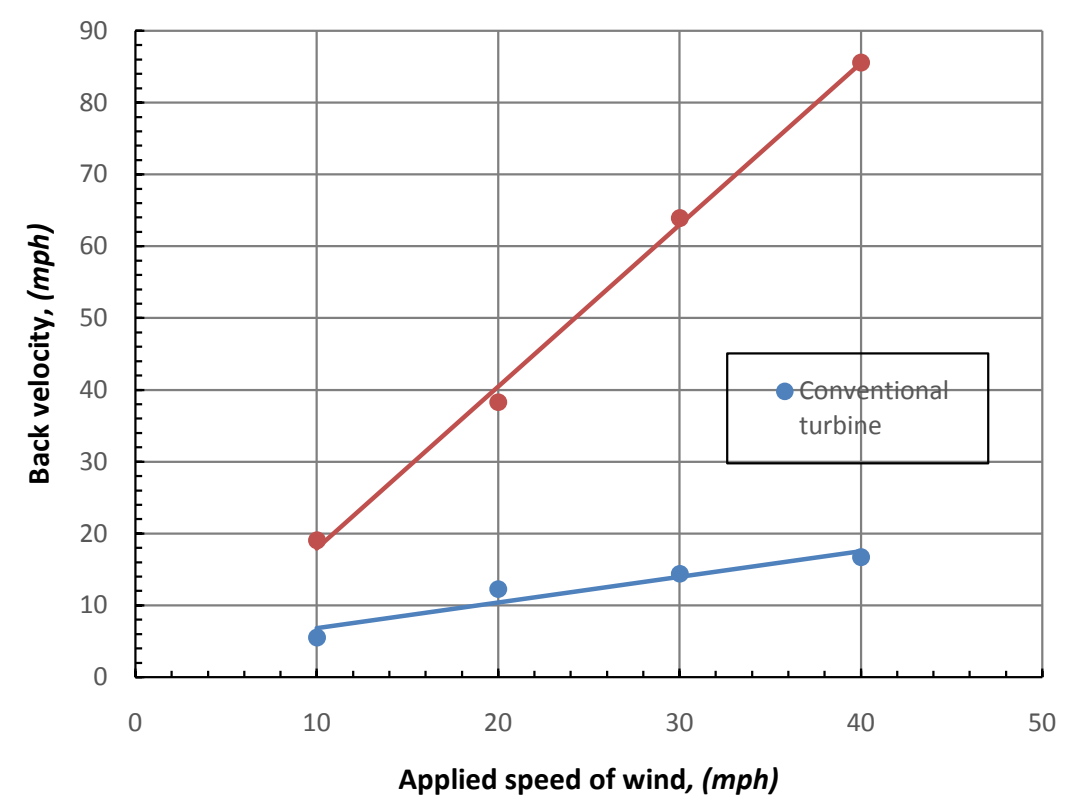

Figure 18. Applied speeds of winds against back velocities.

velocities, the kinetic energy of winds gets consumed by the blade; this is translated into a decrease in the back pressure. When looking at Table 8, it is noticeable that the increase in the back velocity is not that large due to losses in the energy of winds since a part of it is dispersed far way of the blades. Also, when increasing the value of the applied velocity of wind, the increase in the back velocity is not that large. For example, when applying a velocity of $40 \mathrm{mph}$, the resulting back velocity is $16.708 \mathrm{mph}$, which is not that large when compared to the resulted value when applying the same value with the existence of the shroud.

However, according to Table 9, and Figure 18, when applying the same values of velocities of winds on the shrouded turbine, it is clear that because of the shroud the pressure behind the blades gets lowered more than the back pressure that was measured behind the blades of the conventional turbine. That is, increasing the back velocity due to the low-pressure region that caused by the brim at the end of the shroud. This translated into the increase of the back velocity's value when applying, for example, a wind speed of $40 \mathrm{mph}$. When comparing both values of back velocities for both turbines at same applied speed of wind, it is clear that the measured value of the back velocity of the shrouded wind- $85.62 \mathrm{mph}$ - is higher than that value for the conventional turbine which is $16.708 \mathrm{mph}$. This increases the velocity of the flow at the entrance of the shroud, causing an increase in the produced power.

\subsection{Produced Power}

As shown in Figure 19, and in Table 10 and Table 11, there are huge differences in the produced power by both conventional turbine and shrouded turbine. The two carves show the produced power from both turbines when applying different wind speeds. For the conventional wind turbine, the produced power varies from 50.09 $\mathrm{kW}$ up to $3227 \mathrm{~kW}$; the values of the produced power are shown as the blue carve in Figure 19.

While for the same applied speed on the shrouded turbine, the produced power is much more than the produced power by the conventional turbine. The values of produced power by the shrouded wind turbine vary from $781.7 \mathrm{~kW}$ up to $23,291 \mathrm{~kW}$ which are much larger compared to those for the conventional wind turbine. As mentioned in this research paper, the boost in produced power of the shrouded turbine is because of the lowpressure region behind the brim. Also, because of the design of the diffuser, the pressure of the entering flow 
Table 9. Applied speeds of winds on shrouded wind turbine and back velocities over blades’ surface.

\begin{tabular}{cccc}
\hline Applied wind speed $(m p h)$ & 10 & 20 & 30 \\
Back velocity $(m p h)$ & 19.042 & 38.298 & 63.953 \\
\hline
\end{tabular}

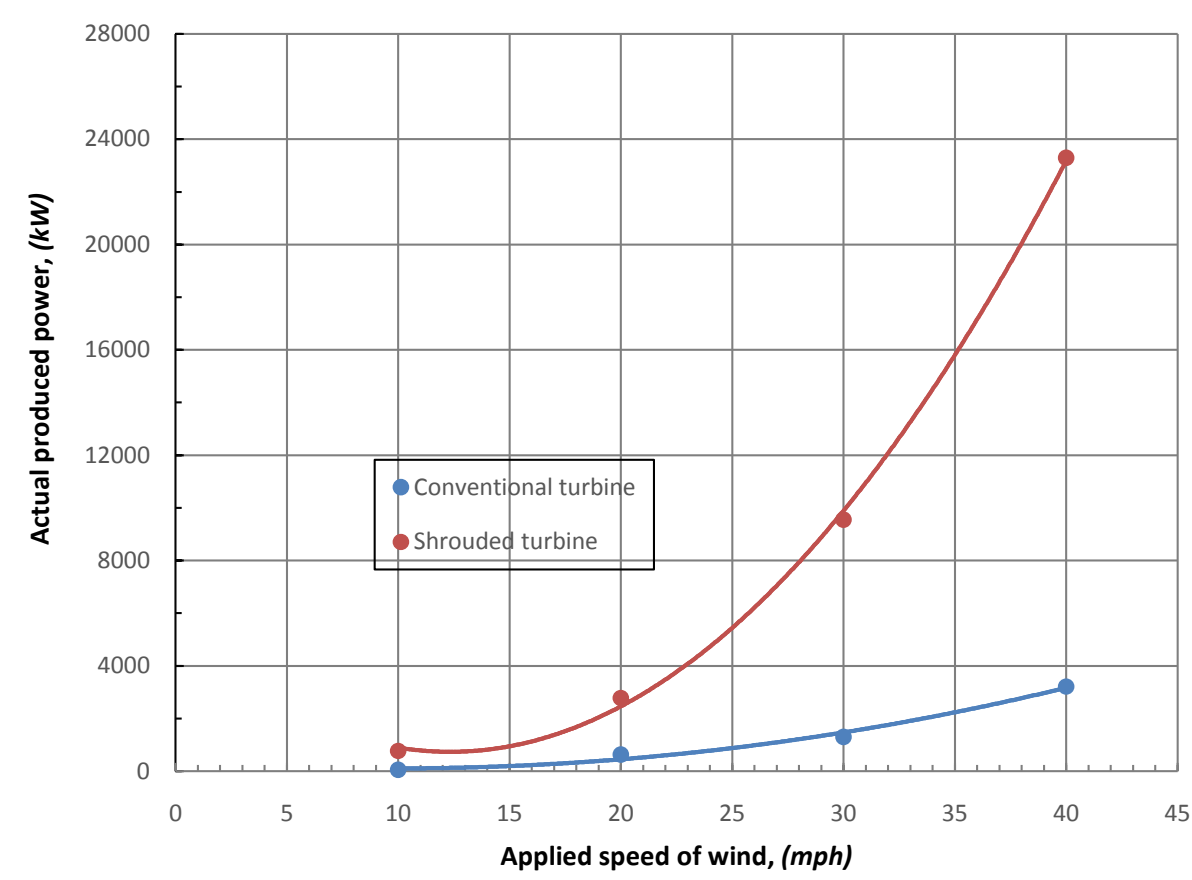

Figure 19. Applied speeds of winds against actual produced power.

Table 10. Applied and front speeds of winds on conventional wind turbine and actual produced power.

\begin{tabular}{ccccc}
\hline Applied wind speed $(\mathrm{mph})$ & 10 & 20 & 30 & 40 \\
Front Speed $(\mathrm{m} / \mathrm{s})$ & 3.9191 & 9.1178 & 11.5962 & 15.7108 \\
Actual produced power $(\mathrm{kW})$ & 50.09 & 630.7 & 1298 & 3227 \\
\hline
\end{tabular}

Table 11. Applied and front speeds of winds on shrouded wind turbine and actual produced power.

\begin{tabular}{ccccc}
\hline Applied wind speed $(m p h)$ & 10 & 20 & 30 \\
Front speed $(m / s)$ & 9.794 & 14.973 & 22.558 \\
Actual produced power $(k W)$ & 781.7 & 2793 & 9551 \\
\hline
\end{tabular}

decreases, causing an increase in the speed of the flow towards the blades of the turbine (Front speed) and results in an increases in the produced power by the generator.

\section{Conclusion}

Since conventional power plants have a destructive effect on the environment and because of they are not available at some places around the world, scientists and engineers have focused on developing other alternative resources of energies. One of these sources of energies is wind energy. Wind energy has been developed using different designs or configurations to get the maximum benefits. Configurations such as conventional horizontal-axis wind turbines, and shrouded wind turbines are good examples for the development of winds energy. All these configurations work on the same principle of converting the wind energy into electrical power. When analyzing all the previous designs and configurations, there is a large variation of the output power from the same size turbine. For the same wind speed, the power output from the shrouded wind turbine exceeds that of the conventional wind turbine. 


\section{Recommendations}

In this report, the power output of the conventional and shrouded wind turbines configurations were compared to each other with varying wind speeds. The two turbines have the same basic design, but the output power was increased with the addition of a shroud. Designing such a huge shrouded wind turbine as analyzed in this report is possible. However, the electrical power that is produced by the conventional turbine can be obtained from a smaller sized shrouded wind turbine. In different words, the shrouded turbine with a large diffuser and longer brim would result in a heavy structure, which is not desirable from a practical standpoint. Thus, continued research is needed to overcome these issues for utilizing the shrouded wind turbines. For example, when considering the vast areas that are occupied by conventional wind turbines, power companies could utilize smaller shrouded wind turbines for the same power output and reduce the land required and the overall cost of the system.

\section{References}

[1] Cairns, J.R. (1972) Heated Waste Water Discharges from Steam-Power Plants. Bioscience, 22, 411-419+423. http://dx.doi.org/10.2307/1296225

[2] Sathyajith, M. and Philip, G.S. (2011) Advances in Wind Energy Conversion Technology. Sprint, New York. http://dx.doi.org/10.1007/978-3-540-88258-9

[3] Jha, A.R. (2011) Wind Turbine Technology. CRC Press, New York.

[4] Manwell, J.F. and McGowan, A.L. (1993) Wind Energy Explained: Theory, Design and Application. John Wiley \& Sons, New York.

[5] Tong, W. (2010) Wind Power Generation and Wind Turbine Design. WIT Press, Ashurst.

[6] Green, C. (2009) Ducted or Augmented Turbines. http://www.wind-works.org

[7] Earnest, J. and Wizelius, T. (2011) Wind Power Plants \& Product Development. PHI Learning, Delhi.

[8] Ohya, Y. and Karasudani, T. (2010) A Shrouded Wind Turbine Generating High Output Power with Wind-Lens Technology. Energies, 3, 634-649. http://dx.doi.org/10.3390/en3040634

[9] Duffie, J.A. and Beckman, W.A. (2013) Solar Engineering of Thermal Processes. John Wiley \& Sons, Hoboken. http://dx.doi.org/10.1002/9781118671603

\section{Nomenclature}

$\mathrm{A}_{\text {rotor: }}$ : Rotor area

$\mathrm{C}_{\mathrm{F}}$ : Capacity factor

$D$ : Throat diameter

Dr: Rotor diameter

$E_{\text {annual: Annual energy }}$

$E_{\text {wind }}$ : Wind energy

$h$ : Brim height

$L$ : Blade distance

$L t$ : Shroud depth

$\bar{P}_{a c t}:$ Average actual produced power

Pr: Rated power

$\bar{P} r$ : Average rated power

$\bar{P}_{\text {wind }}$ : Average wind power

$S$ : Shroud tolerance

$\bar{v}$ : Average frontal airspeed

$\bar{v}_{r}$ : Average rated speed

$\eta$ : Efficiency

$\rho_{\text {air }}$ : Air density 


\section{Submit or recommend next manuscript to SCIRP and we will provide best service for you:}

Accepting pre-submission inquiries through Email, Facebook, LinkedIn, Twitter, etc.

A wide selection of journals (inclusive of 9 subjects, more than 200 journals)

Providing 24-hour high-quality service

User-friendly online submission system

Fair and swift peer-review system

Efficient typesetting and proofreading procedure

Display of the result of downloads and visits, as well as the number of cited articles

Maximum dissemination of your research work

Submit your manuscript at: http://papersubmission.scirp.org/ 